\title{
Controle de plantas daninhas na cultura da canola com diferentes herbicidas
}

\section{Control of canola crop weeds with different herbicides}

Leandro Galon ${ }^{*}$, Jean M. R. da Silva ${ }^{a}$, Emanuel L. Favretto ${ }^{a}$, Daiani Brandler ${ }^{b}$, Sabrina N. Weirich ${ }^{a}$, Daniel C. Cavalettia, Ricardo Martins Junior ${ }^{\mathrm{a}}$ a Laboratório Manejo Sustentável dos Sistemas Agrícolas, Universidade Federal da Fronteira Sul, Rio Grande do Sul, Brasil. ${ }^{\text {b} P r o g r a m a ~ d e ~ P o ́ s-~}$
Graduação em Agronomia, Universidade Tecnológica Federal do Paraná, Pato Branco, Brasil.

Resumo: Introdução: A interferência das plantas daninhas na cultura da canola ocasiona prejuízos, como a redução da produtividade e da qualidade dos grãos.

Objetivo: Avaliar a eficácia de herbicidas aplicados para o controle de plantas daninhas em canola e o efeito sobre o rendimento de grãos da cultura.

Métodos: Foram instalados dois ensaios a campo, um (I) no ano agrícola de 2018 e outro (II) em 2019, em delineamento de blocos ao acaso, com 17 tratamentos e quatro repetições. Os híbridos de canola estudados foram a Hyola 571 CL e a Hyola 575 CL (Clearfield ${ }^{\circledR}$ ). Nos dois experimentos testou-se os herbicidas: iodosulfuron, imazethapyr+imazapic, imazapic+imazapyr, imazethapyr, pyroxsulam, nicosulfuron, imazamox, diclosulam, imazaquin, chlorimuron-ethyl, sulfentrazone, sulfentrazone+diuron, pendimethalin, metsulfuron-methyl e flumioxazin, mais duas testemunhas, uma capinada e outra infestada. O azevém e nabo foram as plantas daninhas presentes na área experimental. Aos 7, 14, 21, 28 e 35 dias após aplicação dos tratamentos (DAT) foi avaliado o controle das plantas daninhas. Após a colheita determinou-se o peso de mil grãos e a produtividade.

Resultados: O imazapic+imazapyr e o nicosulfuron apresentam o melhor controle do azevém nos dois ensaios. O iodosulfuron, imazethapyr+imazapic, imazapic+imazapyr, nicosulfuron, diclosulam, chlorimuron-ethyl e metsulfuron-methyl foram os tratamentos que melhor controlaram o nabo nos experimentos I e II.

Conclusões: As maiores produtividades de grãos de canola foram obtidas com a aplicação de nicosulfuron e imazaquin para a Hyola 571 CL e de imazethapyr para o híbrido Hyola 575 CL.

Palavras-chave: Brassica napus L. var. oleifera, hyola, tecnologia clearfield ${ }^{\circledR}$.
Abstract: Background: Weed interference in canola crop causes losses such as reduced grain yield and quality.

Objective: The aim of this study was to evaluate the efficacy of herbicides applied for weed control in canola and the effect on crop grain yield.

Methods: Two experiments were installed, first (I) in 2018 crop season, and second (II) in 2019, in completely randomized design, with 17 treatments and four replications each. Experiment I was installed with canola hybrid Hyola 571 CL $\left(\right.$ Clearfield $^{\circledR}$ ), and experiment II with Hyola 575 CL. In both tests the herbicides were: iodosulfuron, imazethapyr+imazapic, imazapic+imazapyr, imazethapyr, pyroxsulam, nicosulfuron, imazamox, diclosulam, imazaquin, chlorimuron-ethyl, sulfentrazone, sulfentrazone+diuron, pendimethalin, metsulfuron-methyl, and flumioxazin, plus two Control treatments, one free from infestation and other infested. Weeds present in the experimental area were ryegrass and turnip. At 7, 14, 21,28 , and 35 days after treatment application (DAT) weed control was assessed. After harvesting, the weight of a thousand grains and grains yield were determined.

Results: Imazapic+imazapyr and nicosulfuron presented the best control of ryegrass in both experiments. Iodosulfuron, imazethapyr+imazapic, imazapic+imazapyr, nicosulfuron, diclosulam, chlorimuron-ethyl, and metsulfuron-methyl were treatments that best controlled turnip in both experiments.

Conclusions: The highest grain yield for Hyola 571 CL was obtained with application of nicosulfuron and imazaquin, and for Hyola 575 CL with application of imazethapyr.

Keywords: Brassica napus L. var. oleifera, hyola, clearfield ${ }^{\circledR}$ technology.

\section{Journal Information:}

ISSN: $2763-8332$

Website: https://www.weedcontroljournal.org/

Jornal da Sociedade Brasileira da Ciência das Plantas Daninhas

Como citar: Galon L, Silva JMR, Favretto EL, Brandler D, Weirich SN, Cavaletti DC, Martins Junior R. Controle de plantas daninhas na cultura da canola com diferentes herbicidas. Weed Control J. 2021;20:e20210074:1.

https://doi.org/10.7824/wcj.2021;20:0074.1

\section{Aprovado por:}

Editor-Chefe: Daniel Valadão Silva

Editor Associado: André Ulguim

Conflitos de interesse: Os autores declaram não haver conflito de interesses em relação à publicação deste manuscrito.

Recebido: Novembro 18, 2020

Aprovado: Maio 19, 2021

* Corresponding author:

<leandro.galon@uffs.edu.br>

\section{(c) (1)}

Este é um artigo de acesso aberto distribuído sob os termos da Licença de Atribuição Creative Commons, que permite o uso irrestrito, distribuição e reprodução em qualquer meio, desde que o autor original e a fonte sejam creditados.

Copyright: 2021

\section{Introdução}

A canola (Brassica napus L. var. oleifera) é uma alternativa para cultivo de inverno, para rotação de culturas, melhor aproveitamento da infraestrutura da propriedade, sendo uma importante fonte de proteína, óleo, destinados a alimentação humana e animal ou mesmo para produção de biodisel. A produtividade média dessa cultura esta muito abaixo de lavouras que adotam elevados indices tecnológicos e dentre os fatores que ocasionam isso destaca-se a interferência efetuada pelas plantas daninhas (Durigon et al., 2019).

Dentre as principais culturas de inverno, a canola quando comparada com o trigo e a cevada, apresenta baixa capacidade competitiva pelos recursos água, luz e nutrientes quando infestada por plantas daninhas (Harker et al., 2013). Entre as plantas daninhas que infestam as culturas de inverno e que causam elevados prejuízos na produtividade e qualidade dos grãos, destaca-se nas lavouras na região Sul do Brasil, o nabo/nabiça (Raphanus raphanistrum e $R$. sativum) e o azevém (Lolium multiflorum) (Galon et al., 2015). O nabo/nabiça e o azevém quando não controlados causam perdas na produtividade de grãos da canola de até 90 e $70 \%$, respectivamente (Blackshaw et al., 2002). Além disso, essas espécies são utilizadas frequentemente como plantas voltadas a cobertura de inverno ou como forrageiras e portanto, deixam um grande banco de sementes no solo para ressemeadura natural (Galon et al., 2015).

As plantas daninhas mais competitivas, pelos recursos do meio, em uma lavoura, normalmente são as que pertencem à mesma família botânica da cultura, pois apresentam necessidades similares de recursos (Agostinetto et al., 2010). Desta forma as espécies $R$. sativus e $R$. raphanistrum pelas semelhanças morfofisiológicas 
que apresentam com a canola, além da competição tem demonstrado dificuldades de manejo ao se usar herbicidas (Durigon et al., 2016).

Dentre as estratégias de controle, o método químico tem sido o mais utilizado, pela eficácia, praticidade e baixo custo, quando comparado a outros métodos de manejo de plantas daninhas (Timossi; Freitas, 2011). Porém há poucos herbicidas registrados para o controle de plantas daninhas infestantes da canola que sejam seletivos e de aplicação em pós emergência (Agrofit, 2021), o que ocasiona dificuldade no manejo da comunidade infestante. Diante disso o presente estudo buscou testar vários herbicidas com possibilidades de uso, mesmo que esses não apresentem registro para o controle de plantas daninhas infestantes da canola.

A introdução de híbridos de canola resistentes a herbicidas do grupo químico das imidazolinonas, inibidores de ALS (aceto lactato sintetase), proporcionou uma mudança estratégica no manejo das plantas daninhas, além do que normalmente o processo de melhoramento genético proporciona aumento da produtividade e qualidade dos grãos (Durigon et al., 2019).

Esse mecanismo de ação utilizado para o controle de plantas em culturas com a tecnologia Clearfield ${ }^{\circledR}$, inibem a enzima ALS, responsável pela síntese de aminoácidos de cadeia ramificada, valina, leucina e isoleucina (Tan et al., 2005). A criação da tecnologia Clearfield ${ }^{\circledR}$ foi resultado de uma mutação induzida sobre as plantas de canola, onde as mesmas receberam doses do herbicida imazamox a fim de selecionar plantas mutantes resistentes às imidazolinonas (Tan et al., 2005). Os híbridos Hyola 571 CL $^{\circledR}$ e Hyola $575 \mathrm{CL}^{\circledR}$ foram obtidos através de melhoramento genético clássico, não sendo transgênicas (Tan et al., 2005), sendo o herbicida registrado para o controle de plantas daninhas mono e dicotiledôneas infestantes da canola $\mathrm{CL}^{\circledR} \mathrm{O}$ imazamox pertencente ao grupo das imidazolinonas inibidor de ALS (Rodrigues; Almeida, 2018). Os herbicidas inibidores da enzima ALS são os que apresentam mais casos de biótipos de plantas daninhas resistentes (Heap, 2021). Assim sendo recomenda-se rotacionar tanto ingredientes ativos quanto mecanismos de ação para evitar maiores problemas com casos de resistência. A hipótese da pesquisa é que existe diferenciação na eficácia dos herbicidas aplicados para o controle de plantas daninhas infestantes dos híbridos de canola Hyola $571 \mathrm{CL}$ e $575 \mathrm{CL}$ e que estes possam afetar o rendimento de grãos da cultura. Diante do exposto o objetivo do trabalho foi avaliar a eficácia de herbicidas aplicados para o controle de plantas daninhas em canola e o efeito sobre o rendimento de grãos da cultura.

\section{Material e Métodos}

Os ensaios foram conduzidos a campo, na área experimental da Universidade Federal da Fronteira Sul, Campus Erechim/RS, sendo um conduzido no ano agrícola
2018 e outro experimento em 2019. O solo da área experimental é classificado como Latossolo Vermelho Aluminoférrico típico (Embrapa, 2013), com as seguintes características físico-químicas: $\mathrm{pH}$ em água de 5,1 ; $\mathrm{MO}=3,0 \% ; \mathrm{P}=5,2 \mathrm{mg} \mathrm{dm}{ }^{-3} ; \mathrm{K}=118,0 \mathrm{mg} \mathrm{dm}^{-3} ; \mathrm{Al}^{3+}=0,3$ $\mathrm{cmol}_{\mathrm{c}} \mathrm{dm}^{-3} ; \mathrm{Ca}^{2+}=5,5 \mathrm{cmol}_{\mathrm{c}} \mathrm{dm}^{-3} ; \mathrm{Mg}^{2+}=3,0 \mathrm{cmol}_{\mathrm{c}} \mathrm{dm}^{-3} ;$ $\mathrm{CTC}_{\text {efetiva }}=8,6 \mathrm{cmol}_{\mathrm{c}} \mathrm{dm}^{-3} ; \mathrm{CTC}_{\mathrm{pH}}=16,6 \mathrm{cmol}_{\mathrm{c}} \mathrm{dm}^{-3}$; $\mathrm{H}+\mathrm{Al}=7,7 \mathrm{cmol}_{\mathrm{c}} \mathrm{dm}^{-3}$; Saturação de bases $=53 \%$; e Argila $=$ $60 \%$. A semeadura dos dois experimentos foi realizada em sistema de plantio direto e a correção da fertilidade realizada com base na análise química e seguindo-se as recomendações de calagem e adubação para a cultura da canola (Rolas, 2016).

Os ensaios foram instalados em delineamento experimental de blocos casualizados, com quatro repetições e 17 tratamentos. Cada unidade experimental teve dimensões de $3 \times 5 \mathrm{~m}$, totalizando uma área de $15 \mathrm{~m}^{2}$, contendo 6 linhas de semeadura espaçadas em $0,5 \mathrm{~m}$, sendo que as sementes foram depositadas no sulco a uma profundidade de 2 a $3 \mathrm{~cm}$. A área útil $\left(8 \mathrm{~m}^{2}\right)$ das parcelas corresponderam as 4 linhas centrais, descartando-se as bordaduras laterais (uma linha em cada lado das parcelas) e as frontais (0,5 m no início e fim das parcelas), para a coleta dos dados das variáveis resposta estudadas.

A semeadura do ensaio I ocorreu em 27/06/2018, utilizando-se o híbrido de canola Hyola 575 CL; e o II em 02/07/2019 com a Hyola 571 CL, sendo que ambos foram semeados com semeadora/adubadora de precisão. A densidade média de semeadura foi de 40 sementes $\mathrm{m}^{-2}$ o que resultou em uma população final de, aproximadamente, 400.000 sementes $h^{-1}$. Para adubação de base foi utilizado $350 \mathrm{~kg} \mathrm{ha}{ }^{-1}$ da fórmula 10-20-20 de N-P-K, com aplicação de $80 \mathrm{~kg} \mathrm{ha}{ }^{-1}$ de nitrogênio na forma de ureia aos 40 dias após a emergência da cultura, quando essa estava com quatro a cinco folhas completamente expandidas. Foram utilizados diferentes híbridos de canola (Hyola 571 CL e Hyola 575 CL), testando-se os mesmos herbicidas sobre esses, nos dois anos agrícolas (2018 e 2019), pela dificuldade de se encontrar os mesmos híbridos quando se deseja repetir ensaios a campo, desse modo se teve a duplicidade dos tratamentos aplicados sobre a cultura.

A aplicação dos herbicidas foi realizada com a utilização de um pulverizador costal de precisão, pressurizado a $\mathrm{CO}_{2}$, equipado com quatro pontas de pulverização do tipo leque DG 110.02, mantendo-se a pressão constante de 210 $\mathrm{kPa}$ e velocidade de deslocamento de $3,6 \mathrm{~km} \mathrm{~h}^{-1}$, o que proporcionou a vazão de $150 \mathrm{~L} \mathrm{ha}^{-1}$ de calda de herbicida. A aplicação dos herbicidas em pré-emergência se deu logo após a semeadura da canola, ou seja, no mesmo dia e a aplicação dos herbicidas em pós-emergência ocorreu 30 dias após a semeadura dos híbridos. Os tratamentos e doses utilizados em ambos os ensaios encontram-se dispostos na Tabela 1. As condições ambientais no momento da aplicação dos herbicidas em pré-emergência (28/06/2018 e 02/07/2019) e pósemergência (30/07/2018 e 03/08/2019) da cultura, nos dois ensaios eram favoráveis e podem ser observadas na Tabela 2 . 
Tabela 1. Tratamentos utilizados nos anos agrícolas de 2018 e 2019 em ambos os ensaios, respectivas doses, adjuvantes e modalidade de aplicação.

\begin{tabular}{|c|c|c|c|c|c|}
\hline Tratamentos & $\begin{array}{c}\text { Dose }\left(\mathrm{g} \mathrm{ha}^{-1}\right) \\
\text { i.a ou e.a }\end{array}$ & $\begin{array}{c}\text { Doses } \\
(\mathrm{L} \mathrm{ou} \mathrm{kg} \mathrm{ha-1}) \\
\text { P.C }\end{array}$ & \multicolumn{2}{|c|}{$\begin{array}{c}\text { Adjuvante } \\
(\% \text { v/v ou L) }\end{array}$} & $\begin{array}{l}\text { Época de } \\
\text { Aplicação }\end{array}$ \\
\hline To1- Testemunha capinada & --- & --- & --- & --- & --- \\
\hline To2- Testemunha infestada & --- & --- & -- & --- & --- \\
\hline To3- Iodosulfuron ${ }^{1}$ & 3,5 & 0,07 & Hoefix & $0,5 \mathrm{~L}$ & Pós-emergência \\
\hline To4-Imazethapyr+imazapic ${ }^{2}$ & $75,0+25,0$ & 1,00 & Dash & $0,75 \mathrm{~L}$ & Pós-emergência \\
\hline To5- Imazapic+imazapyr ${ }^{3}$ & $24,5+73,5$ & 0,140 & Dash & $0,75 \mathrm{~L}$ & Pós-emergência \\
\hline To6- Imazethapyr ${ }^{4}$ & 106,0 & 0,500 & Dash & $0,5 \mathrm{v} / \mathrm{v}$ & Pós-emergência \\
\hline To7- Pyroxsulam 5 & 18,0 & 0,400 & Veget'Oil & $0,5 \mathrm{~L}$ & Pós-emergência \\
\hline To8- Nicosulfuron ${ }^{6}$ & 45,0 & 0,06 & Joint Oil & $0,1 \mathrm{~L}$ & Pós-emergência \\
\hline To9- Imazamox ${ }^{7}$ & 42,0 & 0,06 & Dash & --- & Pós-emergência \\
\hline T10- Diclosulam ${ }^{8}$ & 29,4 & 0,035 & --- & --- & Pré-emergência \\
\hline T11- Imazaquin ${ }^{9}$ & 150,0 & 1,0 & --- & --- & Pré-emergência \\
\hline T12- Chlorimuron-ethyl ${ }^{10}$ & 15,0 & 0,06 & Joint Oil & $0,5 \mathrm{v} / \mathrm{v}$ & Pós-emergência \\
\hline T13-Sulfentrazone ${ }^{11}$ & 300,0 & 0,6 & --- & --- & Pré-emergência \\
\hline T14- Sulfentrazone+diuron ${ }^{12}$ & $175,0+350,0$ & 1,00 & --- & --- & Pré-emergência \\
\hline T15- Pendimethalin ${ }^{13}$ & 1200,0 & 3,00 & -- & --- & Pré-emergência \\
\hline T16- Metsulfuron-methyl ${ }^{14}$ & 3,6 & 0,006 & Dash & $0,15 \mathrm{~L}$ & Pós-emergência \\
\hline T17-Flumioxazin ${ }^{15}$ & 25,0 & 0,05 & --- & --- & Pré-emergência \\
\hline
\end{tabular}

i.a: ingrediente ativo. e.a: equivalente acido. P.C: Produto comercial. ${ }^{1}$ Hussar (50 g kg-1, Bayer - WG); ${ }^{2}$ Only (75+25 $\mathrm{g} \mathrm{L}^{-1}$, Basf - SL); ${ }^{3}$ Kifix $\left(175+525 \mathrm{~g} \mathrm{~kg}^{-1}\right.$, Basf - WG); ${ }^{4}$ Imazetapir Nortox $\left(212 \mathrm{~g} \mathrm{~L}^{-1}\right.$, Nortox - SL), ${ }^{5}$ Tricea (45 $\mathrm{g} \mathrm{L}^{-1}$, Dow Agrosciences - XX); ${ }^{6}$ Accent $\left(750 \mathrm{~g} \mathrm{~kg}^{-1}\right.$, Du Pont do Brasil WG); ${ }^{7}$ Raptor $70 \mathrm{DG}\left(700 \mathrm{~g} \mathrm{~kg}^{-1}\right.$, Basf - WG); ${ }^{8}$ Spider $840 \mathrm{WG}$ (840 $\mathrm{g} \mathrm{kg}^{-1}$, Dow Agrosciences WG); ${ }^{9}$ Imazaquim Ultra Nortox (150 $\mathrm{g} \mathrm{L}^{-1}$, Nortox - SL); ${ }^{\circ} \mathrm{Classic}\left(250 \mathrm{~g} \mathrm{~kg}^{-1}\right.$, Du Pont do Brasil WG); Boral $500 \mathrm{SC}$ (500 g L'-1, FMC Química do Brasil - SC); ${ }^{12}$ Stone (175+350 g L-1, FMC Química do Brasil - SC); ${ }^{13}$ Herbadox 400 EC (400 g L-1, Basf - EC); ${ }^{14}$ Ally (600 g kg-1 FMC Química do Brasil - WG) e ${ }^{15}$ Flumyzin 500 (500 $\mathrm{g} \mathrm{kg}^{-1}$, Sumitomo Chemical do Brasil - WP).

Tabela 2. Condições ambientais no momento da aplicação dos tratamentos em pré e pós-emergência da cultura da canola para os dois ensaios com os híbridos, Hyola 571 CL e Hyola 575 CL.

\begin{tabular}{|c|c|c|c|c|c|c|}
\hline Época de aplicação & $\begin{array}{c}\text { Luminosidade } \\
(\%)\end{array}$ & $\begin{array}{c}\text { Temperatura do } \\
\text { ar }-{ }^{\circ} \mathrm{C}\end{array}$ & $\begin{array}{l}\text { Temperatura do } \\
\text { solo }-{ }^{\circ} \mathrm{C}\end{array}$ & $\begin{array}{l}\text { Velocidade do } \\
\text { vento }-\mathrm{km} \mathrm{h}^{-1}\end{array}$ & $\begin{array}{l}\text { Condições do } \\
\text { solo }\end{array}$ & $\begin{array}{l}\text { Umidade } \\
\text { relativa - \% }\end{array}$ \\
\hline \multicolumn{7}{|c|}{ Ano agrícola 2018} \\
\hline Pré-emergência & 100 & 20,1 & 16,1 & 6,5 & Friável & 72,0 \\
\hline Pós-emergência & 100 & 19,0 & 14,1 & 3,4 & Friável & 68,0 \\
\hline \multicolumn{7}{|c|}{ Ano agrícola 2019} \\
\hline Pré-emergência & 100 & 21,9 & 18,1 & 8,5 & Friável & 77,0 \\
\hline Pós-emergência & 100 & 18,0 & 12,1 & 4,2 & Friável & 70,0 \\
\hline
\end{tabular}


As plantas daninhas infestantes da cultura da canola, presentes na área experimental foram, azevém (Lolium multiflorum) e nabo/nabiça (Raphanus raphanistrum e $R$. sativus) ocorrentes na densidade média de 14 e 27 plantas $\mathrm{m}^{2}$, respectivamente. Ao se aplicar os herbicidas em pósemergência a canola estava no estádio B4 (quatro folhas totalmente expandidas), o azevém com 4 folhas a 1 perfilho e o nabo com 4 a 6 folhas, respectivamente.

As avaliações de controle das plantas daninhas (nabo e azevém) foram efetuadas aos 7, 14, 21, 28 e 35 dias após a aplicação dos tratamentos (DAT). Para tanto, foram atribuídas notas percentuais, sendo zero (O\%) aos tratamentos com ausência de controle ou de cem (100\%) para o controle das plantas daninhas de acordo com a metodologia proposta por Velini et al. (1995).

Quando a canola estava com $18 \%$ de umidade, realizou-se a colheita em área de $8 \mathrm{~m}^{2}(2 \times 4 \mathrm{~m})$ em cada unidade experimental, onde foram determinados o peso de mil grãos (g) e a produtividade de grãos $\left(\mathrm{kg} \mathrm{ha}^{-1}\right)$. Utilizando uma balança analítica, determinou-se o peso de mil grãos, contando-se oito amostras de 100 grãos em cada unidade experimental (Brasil, 2009). Posteriormente estimou-se a produtividade de grãos em $\mathrm{kg} \mathrm{ha}{ }^{-1}$. Para estas análises, a umidade dos grãos foi ajustada para 10\% (Tomm et al., 2009). Os dados foram submetidos a análise de variância pelo teste $\mathrm{F}$ e, em havendo significância aplicou-se o teste de Scott-Knott, com $\mathrm{p} \leq 0,05$.

\section{Resultados e Discussão}

Para os dois experimentos instalados nos diferentes anos agrícolas (2018 e 2019) ocorreram efeitos significativos dos tratamentos testados sobre as variáveis; controles de azevém e nabo, para a produtividade de grãos da canola híbridos Hyola 571 CL e Hyola 575 CL (Tabelas 3, 4, 5, 6, 7 e 8). Não houve efeito significativo dos tratamentos somente para o peso de mil grãos da canola Hyola 575 CL para o experimento instalado no ano agrícola de 2018 (Tabela 5).

\section{Ensaio I - ano agrícola 2018}

Nas Tabelas 3 e 4 são apresentadas as porcentagens de controle para as plantas daninhas, azevém e nabo infestantes do híbrido de canola Hyola 575 CL. Os únicos tratamentos que se equivaleram a testemunha capinada e demonstraram controle superior a $80 \%$, foram a mistura comercial composta de imazapic+imazapyr e o nicosulfuron nas avaliações efetuadas aos 14, 21 e 28 dias após a aplicação dos tratamentos - DAT (Tabela 3). Esses mesmos tratamentos aos 7 e 35 DAT também obtiveram índices abaixo do recomendado, ou seja, menos de $80 \%$. Como são herbicidas inibidores de ALS, o efeito dos mesmos sobre as plantas é perceptível aos 14 dias após a aplicação em diante, já que produtos pertecentes a esse mecanismo de ação apresentam efeito lento sobre as plantas (Rodrigues; Almeida, 2018), provavelmente esse foi o motivo que aos 7 DAT o imazapic+imazapyr demonstrou controle de $70 \%$ e o nicosulfuron de $61,25 \%$. Para ser considerado eficiente um herbicida precisa apresentar controle mínimo de 80\%, conforme relatam Oliveira et al. (2009). Sendo assim aos 7 DAT nenhum herbicida pode ser considerado eficiente no controle de azevém.

Após os 35 DAT, o controle de azevém pelos tratamentos imazapic+imazapyr e nicosulfuron reduziu a níveis menores que $78 \%$. Isso provavelmente ocorre em função de novas infestações da planta daninha ocorridas na área, já que essa espécie apresenta germinação desuniforme (Vargas et al., 2018); ou que o residual dos tratamentos tenha reduzido, permitindo assim a emergência de novas plantas.

Os demais tratamentos herbicidas aplicados sobre o azevém apresentaram controle menor que $80 \%$, ou ausência de controle da planta daninha (Tabela 3). Esse fato ocorreu em função de que alguns desses herbicidas (iodosulfuron, imazethapyr+imazapic, imazethapyr, imazamox, pyroxsulam, diclosulam, imazaquin, chlorimuron-ethyl, sulfentrazone, sulfentrazone + diuron, pendimethalin, metsulfuron-methyl e flumioxazin) não apresentam recomendação para controle de azevém (Agrofit, 2021), ou que esse é resistente aos produtos (Vargas et al., 2013). Além disso, também pode ter ocorrido algum fator ambiental que tenha interferido na eficiência do produto, como escasses de chuva (Figura 1), já que os herbicidas, principalmente pré-emergentes, em sua maioria, necessitam de umidade no solo para que exerçam seu efeito, ou seja, controle das plantas daninhas (Torres et al., 2012). Para Lovarelli et al. (2020) as condições climáticas ativam ou inativam as moléculas de herbicidas, dependendo das características dos mesmos na presença de água.

$\mathrm{O}$ azevém é uma espécie muito competitiva com as culturas e também apresenta resistência a herbicidas pertencentes aos mecanismos de ação que inibem a EPSPs, ALS e ACCase (Vargas et al., 2013; Vargas et al., 2018). O trigo, bem como em outras culturas de inverno, a ocorrência de azevém resistente aos inibidores da ALS impossibilita o uso dos herbicidas pertencentes a esse mecanismo de ação (Vargas et al., 2018). Assim a alternativa para controlar azevém restringe-se aos herbicidas inibidores de ACCase, no entanto caso haja biótipos resistentes a esse mecanismo de ação pode representar a impossibilidade de controle em culturas de inverno usando-se o método químico. Desse modo torna-se importante antes da semeadura de trigo o cultivo de milho e/ou sorgo que aportam grandes quantidades de palha que auxilia no controle do azevém ou mesmo o uso de herbicidas do grupo das triazinas (em milho e sorgo) que também apresentam eficiência no controle dessa planta daninha.

O imazapic + imazapyr demonstrou bom controle para o azevém ao longo de todas as avaliações, e isso pode estar relacionado a ação do herbicida, sendo que ele é indicado para cultivares de arroz que apresentam a mesma tecnologia da canola Clearfield. Esse herbicida atua diretamente na redução de três aminoácidos alifáticos de cadeia ramificada, valina, leucina e isoleucina através da inibição do ácido hidroxiacético sintase (AHAS), causando a morte das plantas daninhas (Rodrigues; Almeida, 2018). 
Tabela 3. Controle (\%) de azevém (Lolium multiflorum) em canola, híbrido Hyola 575 CL, em função da aplicação de herbicidas, no agrícola 2018.

\begin{tabular}{|c|c|c|c|c|c|}
\hline \multirow{2}{*}{ Tratamentos } & \multicolumn{5}{|c|}{ Controle de azevém (\%) } \\
\hline & $7 \mathrm{DAT}^{1}$ & 14 DAT & $21 \mathrm{DAT}$ & $28 \mathrm{DAT}$ & $35 \mathrm{DAT}$ \\
\hline To1- Testemunha capinada & $100,00 \mathrm{a}^{2}$ & $100,00 \mathrm{a}$ & $100,00 \mathrm{a}$ & $100,00 \mathrm{a}$ & $100,00 \mathrm{a}$ \\
\hline To2- Testemunha infestada & $0,00 \mathrm{e}$ & $0,00 \mathrm{f}$ & $0,00 \mathrm{~d}$ & $0,00 \mathrm{~d}$ & $0,00 \mathrm{e}$ \\
\hline To3- Iodosulfuron & $56,25 \mathrm{c}$ & $58,75 \mathrm{~d}$ & $52,50 \mathrm{c}$ & $35,00 \mathrm{~b}$ & $46,25 \mathrm{c}$ \\
\hline To4- Imazethapyr+imazapic & $58,75 \mathrm{c}$ & $60,25 \mathrm{~d}$ & $42,50 \mathrm{c}$ & $38,75 \mathrm{~b}$ & $66,25 \mathrm{~b}$ \\
\hline To5- Imazapic+imazapyr & $70,00 \mathrm{~b}$ & 90,00 a & 91,25 a & 90,00 a & $71,25 \mathrm{~b}$ \\
\hline To6- Imazethapyr & $42,50 \mathrm{~d}$ & $61,25 \mathrm{~d}$ & $70,75 \mathrm{~b}$ & $27,50 \mathrm{c}$ & $50,00 \mathrm{c}$ \\
\hline To7- Pyroxsulam & $58,75 \mathrm{c}$ & $77,75 \mathrm{~b}$ & $67,50 \mathrm{~b}$ & $27,50 \mathrm{c}$ & $35,00 \mathrm{~d}$ \\
\hline To8- Nicosulfuron & $61,25 \mathrm{c}$ & 90,25 a & 89,00 a & 93,75 a & $77,50 \mathrm{~b}$ \\
\hline To9- Imazamox & $46,25 \mathrm{~d}$ & $71,25 \mathrm{c}$ & $70,25 \mathrm{~b}$ & $28,75 \mathrm{c}$ & $42,50 \mathrm{c}$ \\
\hline T10- Diclosulam & 0,00 e & $0,00 \mathrm{f}$ & $0,00 \mathrm{~d}$ & $0,00 \mathrm{~d}$ & 0,00 e \\
\hline T11- Imazaquin & $0,00 \mathrm{e}$ & $0,00 \mathrm{f}$ & $0,00 \mathrm{~d}$ & $0,00 \mathrm{~d}$ & $0,00 \mathrm{e}$ \\
\hline T12- Chlorimuron-ethyl & $65,00 \mathrm{~b}$ & $0,00 \mathrm{f}$ & $0,00 \mathrm{~d}$ & $0,00 \mathrm{~d}$ & 0,00 e \\
\hline T13-Sulfentrazone & $72,50 \mathrm{~b}$ & $0,00 \mathrm{f}$ & $0,00 \mathrm{~d}$ & $0,00 \mathrm{~d}$ & $0,00 \mathrm{e}$ \\
\hline T14- Sulfentrazone+diuron & 0,00 e & $0,00 \mathrm{f}$ & $0,00 \mathrm{~d}$ & $0,00 \mathrm{~d}$ & 0,00 e \\
\hline T15-Pendimethalin & $37,50 \mathrm{~d}$ & $43,75 \mathrm{e}$ & $0,00 \mathrm{~d}$ & $0,00 \mathrm{~d}$ & $0,00 \mathrm{e}$ \\
\hline T16- Metsulfuron-methyl & 0,00 e & $0,00 \mathrm{f}$ & $0,00 \mathrm{~d}$ & $0,00 \mathrm{~d}$ & 0,00 e \\
\hline T17- Flumioxazin & $33,75 \mathrm{~d}$ & $0,00 \mathrm{f}$ & $0,00 \mathrm{~d}$ & $0,00 \mathrm{~d}$ & $0,00 \mathrm{e}$ \\
\hline Média Geral & 41,32 & 38,42 & 34,33 & 25,36 & 28,74 \\
\hline CV (\%) & 16,98 & 18,49 & 34,66 & 20,00 & 22,42 \\
\hline
\end{tabular}

${ }^{1}$ DAT: dias após a aplicação dos tratamentos. ${ }^{2}$ Médias seguidas de mesmas letras minúsculas na coluna não diferem entre si pelo teste de Scott-Knott a 5\% de probabilidade.

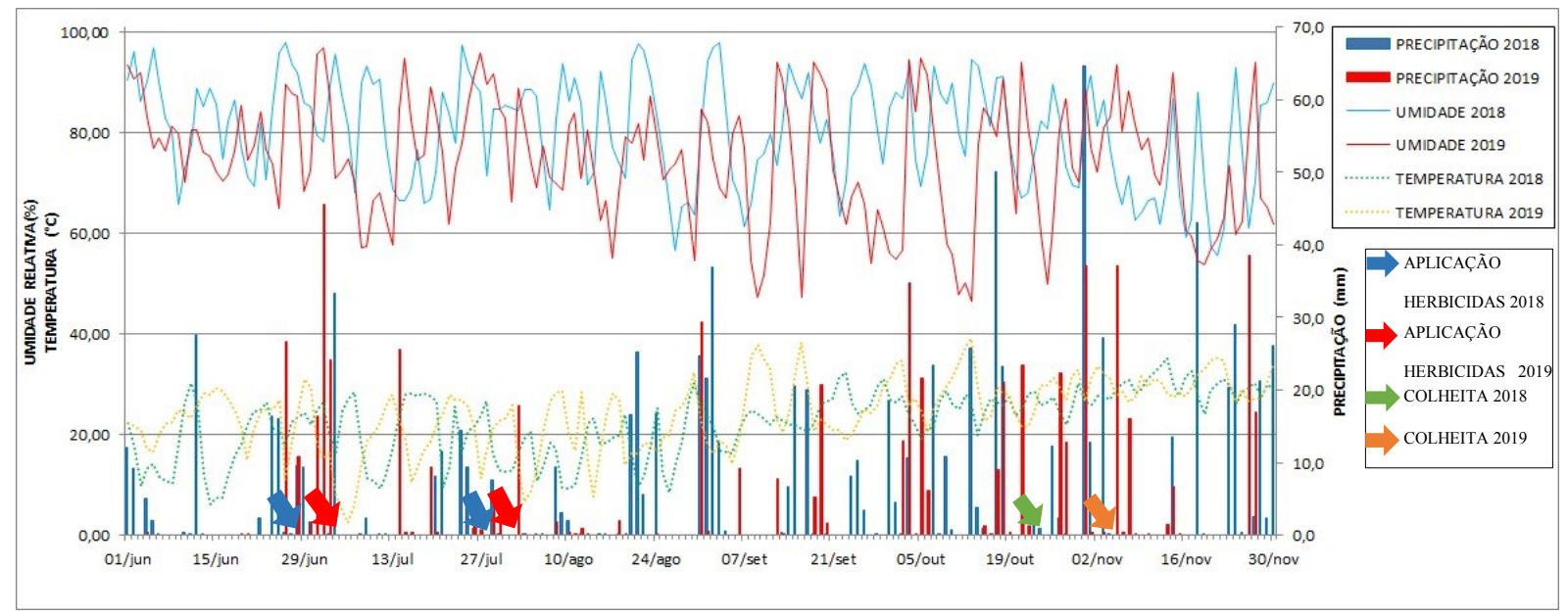

Figura 1. Temperatura média $\left({ }^{\circ} \mathrm{C}\right)$ e precipitação $(\mathrm{mm})$ durante o período de condução dos ensaios nos anos agrícolas 2018 e 2019 (INMET 2020). 
Os resultados indicaram elevada eficiência de praticamente todos os herbicidas, nas avaliações dos 7 aos 35 DAT, exceto para o sulfentrazone, sulfentrazone + diuron, pendimethalin e flumioxazin que demonstram baixos índices de controle do nabo (Tabela 4). Em todas as avaliações (7, 14, 21, 28 e 35 DAT) os herbicidas sulfentrazone e sulfentrazone + diuron não apresentaram controle do nabo (0\%) igualaramse a testemunha infestada, seguidos dos tratamentos que envolveram o pendimethalin e o flumioxazin que demonstram controle inferior a $55 \%$ até os 14 DAT e de $0 \%$ aos 21,28 e 35 DAT. Isso se deve ao fato desses herbicidas (sulfentrazone, sulfentrazone + diuron e pendimethalin) não apresentarem registro para controle de nabo, bem como não ter umidade suficiente no solo para a dissipação dos mesmos, como é o caso do sulfentrazone que depende da disponibilidade de água para degradação da molécula ou até mesmo lixiviá-lo a determinada profundidade (Ohmes et al., 2000).

Tabela 4. Controle (\%) de nabo/nabiça (Raphanus spp.) em canola, híbrido Hyola 575 CL, em função da aplicação de diferentes herbicidas, no ano agrícola 2018.

\begin{tabular}{|c|c|c|c|c|c|}
\hline \multirow{2}{*}{ Tratamentos } & \multicolumn{5}{|c|}{ Controle de nabo (\%) } \\
\hline & $7 \mathrm{DAT}^{1}$ & 14 DAT & $21 \mathrm{DAT}$ & $28 \mathrm{DAT}$ & $35 \mathrm{DAT}$ \\
\hline To1 - Testemunha capinada & $100,00 \mathrm{a}^{2}$ & 100,00 a & $100,00 \mathrm{a}$ & 100,00 a & $100,00 \mathrm{a}$ \\
\hline To2 - Testemunha infestada & $0,00 \mathrm{~g}$ & $0,00 \mathrm{~d}$ & $0,00 \mathrm{e}$ & $0,00 \mathrm{f}$ & $0,00 \mathrm{~d}$ \\
\hline To3 - Iodosulfuron & $82,00 \mathrm{~d}$ & $88,25 \mathrm{~b}$ & $91,25 \mathrm{c}$ & $92,70 \mathrm{c}$ & $90,50 \mathrm{a}$ \\
\hline To4 - Imazethapyr+imazapic & $87,00 \mathrm{c}$ & $94,25 \mathrm{a}$ & $95,50 \mathrm{~b}$ & $92,00 \mathrm{c}$ & 95,00 a \\
\hline To5 - Imazapic+imazapyr & $91,00 \mathrm{~b}$ & 98,25 a & 98,50 a & $95,50 \mathrm{~b}$ & $98,75 \mathrm{a}$ \\
\hline To6 - Imazethapyr & $81,25 \mathrm{~d}$ & $83,25 \mathrm{~b}$ & $93,25 \mathrm{c}$ & $95,00 \mathrm{~b}$ & $79,50 \mathrm{~b}$ \\
\hline To7 - Pyroxsulam & $88,25 \mathrm{c}$ & 93,75 a & $95,00 \mathrm{~b}$ & $90,00 \mathrm{c}$ & $90,00 \mathrm{a}$ \\
\hline To8 - Nicosulfuron & $86,00 \mathrm{c}$ & 96,50 a & $96,50 \mathrm{~b}$ & $95,00 \mathrm{~b}$ & $97,00 \mathrm{a}$ \\
\hline To9 - Imazamox & $87,25 \mathrm{c}$ & 90,75 a & $91,50 \mathrm{c}$ & $83,70 \mathrm{~d}$ & $62,50 \mathrm{c}$ \\
\hline T10 - Diclosulam & 97,50 a & 97,00 a & 97,75 a & $96,25 \mathrm{~b}$ & $98,75 \mathrm{a}$ \\
\hline T11- Imazaquin & $87,25 \mathrm{c}$ & $76,25 \mathrm{~b}$ & $86,75 \mathrm{~d}$ & $91,25 \mathrm{c}$ & $66,75 \mathrm{c}$ \\
\hline T12 - Chlorimuron-ethyl & $91,50 \mathrm{~b}$ & 98,00 a & 99,75 a & $96,50 \mathrm{~b}$ & $100,00 \mathrm{a}$ \\
\hline T13-Sulfentrazone & $0,00 \mathrm{~g}$ & $0,00 \mathrm{~d}$ & $0,00 \mathrm{e}$ & $0,00 \mathrm{f}$ & $0,00 \mathrm{~d}$ \\
\hline T14 - Sulfentrazone+diuron & $0,00 \mathrm{~g}$ & $0,00 \mathrm{~d}$ & $0,00 \mathrm{e}$ & $0,00 \mathrm{f}$ & $0,00 \mathrm{~d}$ \\
\hline T15-Pendimethalin & $30,00 \mathrm{f}$ & $33,75 \mathrm{c}$ & 0,00 e & $0,00 \mathrm{f}$ & $0,00 \mathrm{~d}$ \\
\hline T16 - Metsulfuron-methyl & $91,25 \mathrm{~b}$ & $93,00 \mathrm{a}$ & $96,25 \mathrm{~b}$ & $95, \mathrm{oO} \mathrm{b}$ & $94,50 \mathrm{a}$ \\
\hline T17-Flumioxazin & $51,25 \mathrm{e}$ & $26,25 \mathrm{c}$ & 0,00 e & $0,00 \mathrm{f}$ & $0,00 \mathrm{~d}$ \\
\hline Média Geral & 67,73 & 68,78 & 67,18 & 44,45 & 63,13 \\
\hline $\mathrm{CV}(\%)$ & 5,54 & 10,02 & 3,59 & 36,04 & 9,34 \\
\hline
\end{tabular}

${ }^{1}$ DAT: dias após a aplicação dos tratamentos. ${ }^{2}$ Médias seguidas de mesmas letras minúsculas na coluna não diferem entre si pelo teste de Scott-Knott a $5 \%$ de probabilidade.

O iodosulfuron, imazethapyr+imazapic, imazapic+imazapyr, pyroxsulam, nicosulfuron, diclosulam, chlorimuron-ethyl e metsulfuron-methyl apresentaram controle de nabo dos 7 aos 35 DAT, superior a $80 \%$ e, em algumas situações, estes igualaram-se a testemunha capinada (Tabela 4). Sendo assim, todos os herbicidas relatados anteriormente podem ser recomendados para o controle de nabo infestante da canola Hyola 575 CL. Cechin et al. (2016) também observaram que o iodosulfuron, o imazethapyr, o metsulfuron-methyl, o paraquat e o saflufenacil apresentaram controle de nabo superior a $90 \%$.

Observou-se que o imazethapyr, o imazamox e o imazaquin demonstraram efeitos de controle crescentes e superiores a $80 \%$ até os 28 DAT (Tabela 4), após essa 
avaliação reduziram o índice para 79,50\%; 62,50\% e 66,75\%, respectivamente. Esse fato deve-se, provavelmente, a reinfestação pelo nabo em meio a canola causada pela diminuição do efeito residual desses produtos. Cechin et al. (2016) ao avaliarem o controle de nabo, usando diferentes herbicidas, observaram que o imazethapyr também demonstrou resultado similar ao encontrado no presente estudo.

Galon et al. (2015) perceberam que quanto maior for a densidade de nabo presente em meio a cultura de trigo menor será a área foliar desta. O nabo além de causar perdas na produtividade de grãos também interfere na qualidade do produto e quando não controlado pode ocasionar perdas de até $90 \%$ na produção de canola, estando diretamente relacionado a competição por luz que ocorre entre as plantas (Blackshaw et al., 2002). Caso a canola for destinada para produção de óleo não se recomenda a mistura de grãos de nabo junto a cultura, pois esse tem elevada concentração de ácido erucico que é tóxico para alimentação humana (Santos et al., 2018).

O peso de mil grãos para o híbrido de canola Hyola 575 CL não apresentou resultados significativos (Tabela 5), demonstrando que os tratamentos não alteraram essa variável. O peso de mil grãos da canola é de cerca de 3 a $6 \mathrm{~g}$, variando em função das diferenças genéticas das cultivares ou mesmo pelo efeito de fatores ambientais e de solo (Embrapa, 2009).

Tabela 5. Peso de mil grãos $(\mathrm{g})$ e produtividade de grãos $\left(\mathrm{kg} \mathrm{ha}^{-1}\right)$ de canola, híbrido Hyola $575 \mathrm{CL}$, em função da aplicação de herbicidas, no ano agrícola 2018.

\begin{tabular}{|c|c|c|}
\hline Tratamentos & Peso de mil graãos (g) & Produtividade $\left(\mathrm{kg} \mathrm{ha}^{-1}\right)$ \\
\hline To1- Testemunha capinada & 4,85 ns & 635,19 a \\
\hline To2- Testemunha infestada & 4,72 & $44,58 \mathrm{f}$ \\
\hline To3- Iodosulfuron & 4,37 & $168,46 \mathrm{e}$ \\
\hline To4- Imazethapyr+imazapic & 5,63 & $238,17 \mathrm{~d}$ \\
\hline To5- Imazapic+imazapyr & 5,11 & $477,31 \mathrm{c}$ \\
\hline To6- Imazethapyr & 5,42 & $538,65 \mathrm{~b}$ \\
\hline To7- Pyroxsulam & 4,78 & $441,54 \mathrm{c}$ \\
\hline To8- Nicosulfuron & 4,85 & $464,31 \mathrm{c}$ \\
\hline To9- Imazamox & 5,90 & $435,75 \mathrm{c}$ \\
\hline T10- Diclosulam & 5,37 & $449,92 \mathrm{c}$ \\
\hline T11- Imazaquin & 5,22 & $74,53 \mathrm{f}$ \\
\hline T12- Chlorimuron-ethyl & 4,55 & $8,37 \mathrm{~g}$ \\
\hline T13-Sulfentrazone & 4,66 & $15,95 \mathrm{~g}$ \\
\hline T14- Sulfentrazone+diuron & 4,10 & $44,11 \mathrm{f}$ \\
\hline T15- Pendimethalin & 4,16 & $7,75 \mathrm{~g}$ \\
\hline T16- Metsulfuron-methyl & 4,38 & $38,98 \mathrm{f}$ \\
\hline T17-Flumioxazin & 5,20 & $9,01 \mathrm{~g}$ \\
\hline Média Geral & 4,90 & 240,74 \\
\hline $\mathrm{CV}(\%)$ & 17,56 & 11,68 \\
\hline
\end{tabular}

NS Não significativo. ${ }^{1}$ Médias seguidas de mesmas letras minúsculas na coluna não diferem entre si pelo teste de Scott-Knott a $5 \%$ de probabilidade.

A maior produtividade da cultura com aplicação de herbicidas foi obtida com o uso do imazethapyr, porém quando comparado com a testemunha capinada este apresentou redução de $15,19 \%$ (Tabela 5). Ressalta-se que o imazapic+imazapyr, o nicosulfuron, pyroxsulam, imazamox e diclosulam foram os tratamentos que melhor controlaram o azevém e o nabo e também demonstraram as maiores 
produtividades de grãos entre todos os herbicidas usados, só perdendo para o imazethapyr e a testemunha capinada.

Os herbicidas imazaquin, chlorimuron-ethyl, sulfentrazone, sulfentrazone + diuron, pendimethalin, metsulfuron-methyl e flumioxazin apresentaram produtividades de grãos iguais ou inferiores a testemunha infestada (Tabela 5). Resultados estes que se devem pelo fato desses herbicidas não terem sido eficazes no controle do azevém e/ou nabo, em que as plantas daninhas competiram por nutrientes, água e luz com a cultura, vindo a diminuir significativamente sua produção. Zare et al. (2012) relatam que as plantas daninhas que infestam a canola podem reduzir o rendimento de grãos em 50,84\% quando comparado a área sem infestação. Outra explicação para a baixa produtividade observada da canola, no ano agrícola 2018, pode ter sido em função da escassez de chuvas ocorrida durante o ciclo da cultura, além de ter ocorrido geada no estádio de floração.

As espécies de plantas, a densidade, o genótipo envolvido na competição, os manejos e tratos culturais adotados, as condições edafoclimáticas, além do grau de infestação das plantas daninhas podem afetar significativamente os componentes de produção e a produtividade de grãos da canola (Zuo et al., 2017). Para que não ocorram perdas de produtividade em canola torna-se necessário que se busque um correto manejo, bem como controle eficiente das plantas daninhas que venham a se desenvolver junto com a cultura (Harker et al., 2013).

O imazapic+imazapyr, nicosulfuron, pyroxsulam, imazamox e diclosulam foram os tratamentos que melhor controlaram o azevém e o nabo e que também demonstraram as maiores produtividades de grãos entre todos os herbicidas avaliados, alcançando produtividades menores somente em relação ao imazethapyr e a testemunha capinada na Hyola 575 CL (Tabela 5). Já na Hyola $571 \mathrm{CL}$ os tratamentos que apresentaram os melhores controles de azevém e nabo foram o imazapic + imazapyr e diclosulam, porém as maiores produtividades foram obtidas com o uso dos herbicidas imazaquim e nicosulfuron.

\section{Ensaio II - ano agrícola 2019}

O controle de azevém efetuado nas avaliações dos 7 , 14, 21, 28 e 35 dias após a aplicação dos tratamentos (DAT) esta disposto na Tabela 6. Nenhum dos tratamentos herbicidas apresentou controle estatisticamente igual a testemunha capinada, sendo que dos 21 aos 35 DAT o pyroxsulam, diclosulam, imazaquin, chlorimuron-ethyl, sulfentrazone, pendimethalin, metsulfuron-methyl e o flumioxazin igualaram-se a testemunha infestada, ou seja, ausência de controle. Isso se deve, pelo fato que esses herbicidas não apresentam recomendação para controle de azevém, exceto o pyroxsulam que possui recomendação, mas não demonstrou controle da planta daninha por essa, provalvente, ser resistente aos herbicidas inibidores da ALS (Vargas et al., 2018).

Os herbicidas imazethapyr + imazapic, imazapic + imazapyr, nicosulfuron, imazaquin e pendimethalin apresentaram controle de até $57,5 \%$ aos 7 DAT (Tabela 6). Os demais herbicidas foram superiores somente à testemunha infestada, porém com controle inferior a 50\%. Conforme já comentado para ser considerado eficiente um herbicida precisa apresentar controle mínimo de 80\% (Oliveira et al., 2009) e desse modo na primeira avaliação de controle nenhum produto pode ser considerado eficiente para o controle de azevém.

Aos 14 DAT os herbicidas imazapic+imazapyr, nicosulfuron, imazamox e sulfentrazone+diuron apresentaram controle superior a $70 \%$ (Tabela 6). O iodosulfuron, imazethapyr + imazapic, imazethapyr e sulfentrazone demonstraram controles de 50 até $59,5 \%$. Os herbicidas pyroxsulam, diclosulam, imazaquin, chlorimuronethyl, pendimethalin, metsulfuron-methyl e flumioxazin apresentaram controles abaixo de $50 \%$, sendo que alguns deles não causaram efeito algum de controle de azevém (Tabela 6)

A aplicação de sulfentrazone + diuron demonstrou controle crescente até os 28 DAT, após esse período não apresentou mais efeito sobre o azevém e isso se deve ao fato deste herbicida ser utilizado em pré-emergência, sendo que seus efeitos podem ser influenciados pelo conteúdo de matéria orgânica, tipo e quantidade de argila, valor do $\mathrm{pH}$, além do índice de precipitação pluvial (Oliveira Jr. et al., 2001).

Somente na avaliação dos 21 DAT ocorreu controle de $80 \%$ ou mais de azevém ao se aplicar os herbicidas imazapic + imazapyr, nicosulfuron e sulfentrazone + diuron, os demais apresentaram baixa eficiência variando seu controle. Esse fato pode estar relacionado com o tempo que os produtos levam para demonstrar seus efeitos, o que também foi constatado por Galon et al. (2014) quando avaliaram a eficácia e a fitotoxicidade de herbicidas aplicados para o manejo de plantas daninhas em cevada.

Os herbicidas imazamox, iodosulfuron, imazethapyr, imazethapyr + imazapic apresentaram controles entre 45,0 e $63,5 \%$, já o pyroxsulam, diclosulam, imazaquin, chlorimuronethyl, sulfentrazone, pendimethalin, metsulfuron-methyl e flumioxazin não apresentaram nenhuma porcentagem de controle aos 21 DAT, sendo incapazes de controlar o azévem infestante do híbrido de canola 571 CL, alguns por não controlarem a planta daninha outros pelo fato do azevém ser resistente aos mesmos. Galon et al. (2014) observaram que os herbicidas iodosulfuron, imazethapyr + imazapic, imazapic + imazapyr e pyroxsulam apresentaram controle de azevém superior a $95 \%$ durante todo o ciclo da cultura da cevada.

Nas avaliações aos 28 e 35 DAT os tratamentos que apresentaram os melhores controles foram imazapic + imazapyr e nicosulfuron, respectivamente, sendo que o primeiro demonstrou um aumento gradativo no controle de azevém durante as avaliações (Tabela 6). O sulfentrazone + diuron apresentou mais de $80 \%$ de controle aos 28 DAT e $0 \%$ aos 35 DAT (Tabela 6). Isso pode estar relacionado com a alta pluviosidade que ocorreu alguns dias após a aplicação dos tratamentos, fazendo com que o sulfentrazone permanecesse disponível na solução do solo. Os demais tratamentos não apresentaram controle do azévem, pois além desses herbicidas não possuírem ação residual no solo, não apresentam recomendação para controle dessa planta daninha (Agrofit, 2021). 
Tabela 6. Controle (\%) de azevém (Lolium multiflorum) em canola, híbrido Hyola 571 CL, em função da aplicação de herbicidas, no ano agrícola 2019.

\begin{tabular}{|c|c|c|c|c|c|}
\hline \multirow{2}{*}{ Tratamentos } & \multicolumn{5}{|c|}{ Controle de azevém (\%) } \\
\hline & $7 \mathrm{DAT}^{1}$ & $14 \mathrm{DAT}$ & $21 \mathrm{DAT}$ & $28 \mathrm{DAT}$ & $35 \mathrm{DAT}$ \\
\hline To1- Testemunha capinada & $100,00 \mathrm{a}^{2}$ & $100,00 \mathrm{a}$ & $100,00 \mathrm{a}$ & $100,00 \mathrm{a}$ & $100,00 \mathrm{a}$ \\
\hline To2- Testemunha infestada & $0,00 \mathrm{~d}$ & 0,00 e & 0,00 e & $0,00 \mathrm{e}$ & $0,00 \mathrm{e}$ \\
\hline To3- Iodosulfuron & $42,50 \mathrm{c}$ & $50,00 \mathrm{c}$ & $57,50 \mathrm{c}$ & $43,75 \mathrm{~d}$ & $50,00 \mathrm{e}$ \\
\hline To4- Imazethapyr+imazapic & $50,00 \mathrm{c}$ & $56,25 \mathrm{c}$ & $45, \mathrm{OO} \mathrm{d}$ & $67,50 \mathrm{c}$ & $81,50 \mathrm{c}$ \\
\hline To5- Imazapic+imazapyr & $50,00 \mathrm{c}$ & $78,75 \mathrm{~b}$ & $88,75 \mathrm{~b}$ & $86,75 \mathrm{~b}$ & $93,50 \mathrm{~b}$ \\
\hline To6- Imazethapyr & $46,25 \mathrm{c}$ & $55,00 \mathrm{c}$ & $53,75 \mathrm{~b}$ & $52,50 \mathrm{~d}$ & $60,00 \mathrm{~d}$ \\
\hline To7- Pyroxsulam & $45,00 \mathrm{c}$ & $0,00 \mathrm{e}$ & $0,00 \mathrm{e}$ & $0,00 \mathrm{e}$ & $0,00 \mathrm{e}$ \\
\hline To8- Nicosulfuron & $52,50 \mathrm{c}$ & $70,00 \mathrm{~b}$ & $79,25 \mathrm{~b}$ & $84,50 \mathrm{~b}$ & $78,50 \mathrm{c}$ \\
\hline To9- Imazamox & $42,50 \mathrm{c}$ & $70,00 \mathrm{~b}$ & $63,75 \mathrm{~b}$ & $57,50 \mathrm{c}$ & $56,25 \mathrm{~d}$ \\
\hline T10- Diclosulam & $79,25 \mathrm{~b}$ & $40,00 \mathrm{~d}$ & $0,00 \mathrm{e}$ & $0,00 \mathrm{e}$ & $0,00 \mathrm{e}$ \\
\hline T11- Imazaquin & $57,50 \mathrm{c}$ & $42,50 \mathrm{~d}$ & $0,00 \mathrm{e}$ & $0,00 \mathrm{e}$ & $0,00 \mathrm{e}$ \\
\hline T12- Chlorimuron-ethyl & $35,00 \mathrm{c}$ & $35,00 \mathrm{~d}$ & $0,00 \mathrm{e}$ & $0,00 \mathrm{e}$ & $0,00 \mathrm{e}$ \\
\hline T13-Sulfentrazone & $52,50 \mathrm{c}$ & $59,50 \mathrm{c}$ & $0,00 \mathrm{e}$ & $0,00 \mathrm{e}$ & $0,00 \mathrm{e}$ \\
\hline T14- Sulfentrazone+diuron & $43,75 \mathrm{c}$ & $70,00 \mathrm{~b}$ & $81,25 \mathrm{~b}$ & $82,50 \mathrm{~b}$ & $0,00 \mathrm{e}$ \\
\hline T15-Pendimethalin & $50,00 \mathrm{c}$ & $41,75 \mathrm{~d}$ & $0,00 \mathrm{e}$ & $0,00 \mathrm{e}$ & $0,00 \mathrm{e}$ \\
\hline T16- Metsulfuron-methyl & $36,25 \mathrm{c}$ & $0,00 \mathrm{e}$ & $0,00 \mathrm{e}$ & $0,00 \mathrm{e}$ & $0,00 \mathrm{e}$ \\
\hline T17-Flumioxazin & $40,00 \mathrm{c}$ & $0,00 \mathrm{e}$ & $0,00 \mathrm{e}$ & $0,00 \mathrm{e}$ & $0,00 \mathrm{e}$ \\
\hline Média Geral & 48,41 & 45,22 & 33,48 & 33,82 & 30,57 \\
\hline CV (\%) & 20,51 & 19,57 & 22,14 & 27,08 & 14,53 \\
\hline
\end{tabular}

${ }^{1}$ DAT: dias após a aplicação dos tratamentos. ${ }^{2}$ Médias seguidas de mesmas letras minúsculas na coluna não diferem entre si pelo teste de Scott-Knott a $5 \%$ de probabilidade.

Pereira et al. (2017) ao estudarem o controle químico de Lolium multiflorum, observaram que os herbicidas glyphosate, tepraloxydim, iodosulfuron, paraquat+diuron, paraquat, clodinafop-propargyl, fenoxaprop+clethodim, clethodim e sethoxydim apresentaram variação na porcentagem de controle. Ocorreu mais de $85 \%$ de eficiência somente quando a aplicação foi efetuada no momento em que o azevém estava com 3 a 4 folhas; já quando esses herbicidas foram avaliados no pré-florescimento da planta daninha, os que apresentaram controle eficaz $(>85 \%)$ foram o paraquat, paraquat+diuron, glyphosate e iodosulfuron. Entretanto, esses resultados diferem dos encontrados no presente estudo, em que o iodosulfuron apresentou controle máximo de 57,5\%.

Observou-se que dos 7 aos 35 DAT o herbicida diclosulam foi o que demonstrou maior controle do nabo, equivalendo-se a testemunha capinada (Tabela 7). Aos 14 DAT os herbicidas imazethapyr+imazapic, imazethapyr, nicosulfuron, imazamox, chlorimuron-ethyl e metsulfuron- methyl apresentaram controles superiores a 80\%. Muitos herbicidas inibidores da ALS apresentam injúrias as plantas de modo mais lento e por esse motivo observou-se no presente estudo efeito do pyroxsulam a partir dos 14 DAT. Alguns desses herbicidas além de causarem ação direta nas folhas das plantas, podem também apresentar atividade no solo, podendo persistir e afetar a germinação das sementes ao longo do tempo (Rodrigues; Almeida, 2018).

Os resultados demonstram que a partir dos 21 DAT, somente os herbicidas pyroxsulam, sulfentrazone, sulfentrazone+diuron, pendimethalin e flumioxazin não alcançaram controle superior a $80 \%$, até mesmo alguns deles se igualaram a testemunha infestada (Tabela 7). A alta eficiência no controle do nabo, com o uso do iodosulfuron se deve possivelmente, em função do biótipo presente no experimento ser suscetível ao mecanismo de ação inibidor de ALS (Schmitz et al., 2018). 
Tabela 7. Controle de nabo/nabiça (Raphanus spp.) em canola, híbrido Hyola 571 CL, em função da aplicação de diferentes herbicidas, no ano agrícola 2019.

\begin{tabular}{|c|c|c|c|c|c|}
\hline \multirow{2}{*}{ Tratamentos } & \multicolumn{5}{|c|}{ Controle de nabo (\%) } \\
\hline & $7 \mathrm{DAT}^{1}$ & 14 DAT & $21 \mathrm{DAT}$ & $28 \mathrm{DAT}$ & $35 \mathrm{DAT}$ \\
\hline To1- Testemunha capinada & $100,00 \mathrm{a}^{2}$ & $100,00 \mathrm{a}$ & $100,00 \mathrm{a}$ & $100,00 \mathrm{a}$ & $100,00 \mathrm{a}$ \\
\hline To2- Testemunha infestada & $0,00 \mathrm{e}$ & $0,00 \mathrm{e}$ & $0,00 \mathrm{f}$ & $0,00 \mathrm{f}$ & $0,00 \mathrm{e}$ \\
\hline To3- Iodosulfuron & $57,50 \mathrm{c}$ & $66,25 \mathrm{c}$ & $91,50 \mathrm{c}$ & $95,25 \mathrm{~b}$ & $96,25 \mathrm{~b}$ \\
\hline To4- Imazethapyr+imazapic & $58,75 \mathrm{c}$ & $84,25 \mathrm{~b}$ & $94,25 \mathrm{c}$ & $96,5 \mathrm{ob}$ & $95,75 \mathrm{~b}$ \\
\hline To5- Imazapic+imazapyr & $67,50 \mathrm{c}$ & $77,00 \mathrm{~b}$ & $97,00 \mathrm{~b}$ & $99,00 \mathrm{a}$ & 99,75 a \\
\hline To6- Imazethapyr & $56,25 \mathrm{c}$ & $84,50 \mathrm{~b}$ & $92,50 \mathrm{c}$ & $93,75 \mathrm{~b}$ & $93,50 \mathrm{~b}$ \\
\hline To7- Pyroxsulam & $37,50 \mathrm{~d}$ & $47,50 \mathrm{~d}$ & $0,00 \mathrm{f}$ & $40,00 \mathrm{e}$ & $0,00 \mathrm{e}$ \\
\hline To8- Nicosulfuron & $58,75 \mathrm{c}$ & $84,25 \mathrm{~b}$ & $93,50 \mathrm{c}$ & $95,75 \mathrm{~b}$ & $93,75 \mathrm{~b}$ \\
\hline To9- Imazamox & $45,00 \mathrm{~d}$ & $82,25 \mathrm{~b}$ & $93,75 \mathrm{c}$ & $89,00 \mathrm{c}$ & $87,25 \mathrm{c}$ \\
\hline T10- Diclosulam & 99,00 a & 98,25 a & 99,00 a & 99,25 a & 98,50 a \\
\hline T11- Imazaquin & $80,00 \mathrm{~b}$ & $69,50 \mathrm{c}$ & $87,75 \mathrm{~d}$ & $86,50 \mathrm{~d}$ & $84,75 \mathrm{c}$ \\
\hline T12-Chlorimuron-ethyl & $56,25 \mathrm{c}$ & $85,75 \mathrm{~b}$ & $97, \mathrm{oob}$ & 98,75 a & $100,00 \mathrm{a}$ \\
\hline T13-Sulfentrazone & $67,50 \mathrm{c}$ & $45,00 \mathrm{~d}$ & $0,00 \mathrm{f}$ & $0,00 \mathrm{f}$ & $0,00 \mathrm{e}$ \\
\hline T14- Sulfentrazone+diuron & $45,00 \mathrm{~d}$ & $60,00 \mathrm{c}$ & $79,75 \mathrm{e}$ & $0,00 \mathrm{f}$ & $60,75 \mathrm{~d}$ \\
\hline T15-Pendimethalin & $36,25 \mathrm{~d}$ & $0,00 \mathrm{e}$ & $0,00 \mathrm{f}$ & $0,00 \mathrm{f}$ & $0,00 \mathrm{e}$ \\
\hline T16- Metsulfuron-methyl & $60,00 \mathrm{c}$ & $85,75 \mathrm{~b}$ & $95,00 \mathrm{c}$ & $94,75 \mathrm{~b}$ & $96,00 \mathrm{~b}$ \\
\hline T17- Flumioxazin & $35,00 \mathrm{~d}$ & $0,00 \mathrm{e}$ & $0,00 \mathrm{f}$ & $0,00 \mathrm{f}$ & 0,00 e \\
\hline Média Geral & 56,48 & 62,95 & 65,94 & 64,02 & 65,07 \\
\hline CV $(\%)$ & 16,31 & 16,74 & 2,53 & 2,67 & 3,20 \\
\hline
\end{tabular}

${ }^{1}$ DAT: dias após a aplicação dos tratamentos. ${ }^{2}$ Médias seguidas de mesmas letras minúsculas na coluna não diferem entre si pelo teste de Scott-Knott a $5 \%$ de probabilidade.

Os herbicidas pyroxsulam, sulfentrazone, sulfentrazone+diuron, pendimethalin e o flumioxazin apresentaram índice de controle inferior aos $80 \%$ em todas as avaliações de controle do nabo (Tabela 7). Essa planta daninha apresenta capacidade de rebrote, bem como a retomada do crescimento, pois consegue se recuperar da fitotoxicidade e não ser eficientemente controlada por herbicidas aplicados em pré-emergência (Schmitz et al., 2018). Ao avaliarem a aplicação de clomazone associado ao protetor dietholate para o manejo de plantas daninhas na cultura do trigo observou-se que o efeito desse herbicida sobre o nabo foi superior a $80 \%$, porém ele apresentou capacidade de recuperação dos sintomas fitotóxicos no decorrer das avaliações de controle (Schmitz et al., 2018).

Em todas as épocas avaliadas (7, 14, 21, 28 e 35 DAT) o tratamento que mais se destacou foi o diclosulam, apresentando controle de nabo superior a $98 \%$, fato este que pode estar relacionado com a grande capacidade residual que esse herbicida possui, bem como já foi relatado que o nabo não apresenta resistência a esse mecanismo de ação (Xu et al., 2015). Os piores tratamentos foram pendimethalin e flumioxazin, os quais não chegaram a $40 \%$ de controle do nabo nos 7 DAT e nas demais avaliações não apresentaram nenhuma porcentagem de controle (Tabela 7), pois esses herbicidas não possuem recomendação para controle de nabo.

Para o peso de mil grãos, os tratamentos que se sobressaíram foram o imazaquin e metsulfuron-methyl, apresentando peso de mil grãos $75 \%$ maior que a testemunha capinada (Tabela 8). Todos os demais tratamentos causaram redução nessa variável. Geralmente o peso de mil grãos de canola varia entre 3 a $6 \mathrm{~g}$, sendo que este pode ser determinado pela genética das cultivares, além de sofrer inlfuência das condições do ambiente (Embrapa, 2009), a fitotoxicidade causada pelos herbicidas e a redução de fotoassimilados, podem limitar fisicamente o tamanho dos grãos ou mesmo o peso deles. 
Tabela 8. Peso de mil grãos $(\mathrm{g})$ e produtividade de grãos $\left(\mathrm{kg} \mathrm{ha}^{-1}\right)$ de canola, híbrido Hyola $571 \mathrm{CL}$, em função da aplicação de diferentes herbicidas, no ano agrícola 2019.

\begin{tabular}{|c|c|c|}
\hline Tratamentos & Peso de mil grãos (g) & Produtividade de grãos $\left(\mathrm{kg} \mathrm{ha}^{-1}\right)$ \\
\hline To1- Testemunha capinada & $2,35 \mathrm{c}^{1}$ & $1817,50 \mathrm{~b}$ \\
\hline To2- Testemunha infestada & $0,00 \mathrm{~d}$ & $0,00 \mathrm{~h}$ \\
\hline To3- Iodosulfuron & $2,42 \mathrm{c}$ & $1274,75 \mathrm{c}$ \\
\hline To4- Imazethapyr+imazapic & $2,33 \mathrm{c}$ & $1096,16 \mathrm{c}$ \\
\hline To5- Imazapic+imazapyr & $2,34 \mathrm{c}$ & $1077,83 \mathrm{c}$ \\
\hline To6- Imazethapyr & $2,42 \mathrm{c}$ & $1148,16 \mathrm{c}$ \\
\hline To7- Pyroxsulam & $2,88 \mathrm{c}$ & $236,33 \mathrm{~g}$ \\
\hline To8- Nicosulfuron & $2,06 \mathrm{c}$ & 2359,99 a \\
\hline To9- Imazamox & $2,16 \mathrm{c}$ & $271,91 \mathrm{~g}$ \\
\hline T10- Diclosulam & $3,27 \mathrm{~b}$ & $444,00 \mathrm{f}$ \\
\hline T11- Imazaquin & $4,12 \mathrm{a}$ & 2409,50 a \\
\hline T12- Chlorimuron-ethyl & $3,45 \mathrm{~b}$ & $217,00 \mathrm{~g}$ \\
\hline T13-Sulfentrazone & $0,00 \mathrm{~d}$ & $0,00 \mathrm{~h}$ \\
\hline T14-Sulfentrazone+diuron & $2,44 \mathrm{c}$ & $870,33 \mathrm{~d}$ \\
\hline T15- Pendimethalin & $3,13 \mathrm{~b}$ & $348,00 \mathrm{f}$ \\
\hline T16-Metsulfuron-methyl & 4,13 a & $646,33 \mathrm{e}$ \\
\hline T17-Flumioxazin & $3,16 \mathrm{~b}$ & $182,33 \mathrm{~g}$ \\
\hline Média Geral & 2,51 & 847,07 \\
\hline $\mathrm{CV}(\%)$ & 17,97 & 13,86 \\
\hline
\end{tabular}

${ }^{1}$ Médias seguidas de mesmas letras minúsculas na coluna não diferem entre si pelo teste de Scott-Knott a $5 \%$ de probabilidade.

A aplicação de sulfentrazone ocasionou a morte das plantas de canola do híbrido Hyola 571 CL e desse modo esse tratamento não apresentou peso de mil grãos nem a produtividade de grãos. Esse fato ocorreu devido ao herbicida não ser seletivo e nem registrado para a cultura, causando a morte da mesma. Souza et al. (2014) observaram em crambe (Crambe abyssinica), que pertence à mesma família botânica da canola (Brassicaceae), que o sulfentrazone causou elevada fitotoxicidade às plantas, sendo que tais injúrias foram de $89,5 \%$.

A aplicação de diclosulam, chlorimuron-ethyl, pendimethalin e flumioxazin apresentaram um peso de mil grãos de 3,$27 ; 3,45 ; 3,13$, e 3,16 g, respectivamente, porém sua produtividade foi até $92 \%$ menor que àquela obtida com o uso de imazaquin e nicosulfuron (Tabela 8), sendo esses os tratamentos que mais produziram grãos de canola. Tais resultados podem estar relacionados pelo fato que os herbicidas imazaquin e nicosulfuron não são recomendados para a cultura da canola, e quando aplicados podem exercer efeito fitotóxico às plantas, diminuindo sua capacidade de produzir fotoassimilados e consequentemente interferir na produção de grãos.

O nicosulfuron e o imazaquin, não apresentaram os melhores resultados de controle para o azevém e nabo, porém como já mencionado obtiveram os melhores resultados de produtividade, fato este que pode estar ligado com a capacidade que a cultura possui de superar o estresse causado pelos tratamentos. Robinson et al. (2015) afirmam que as injúrias causadas pelos herbicidas nas plantas são transitórias e por isso podem não afetar a produção final da cultura ou que essa possa vir a se recuperar dos sintomas de fitotoxicidade dos produtos.

As interações entre cultivares, bem como as técnicas agronômicas (densidade de semeadura, espaçamentos, época da aplicação de herbicidas, dentre outros) tem influência sobre a competitividade da canola, fazendo com que ela se sobressaia em relação as plantas daninhas quando bem manejada (Lemerle et al., 2016). Nesse contexto, uma cultivar pode ter elevada capacidade competitiva bem como alta produtividade (Durigon et al., 2019), demonstrando desta 
maneira que esses fatores são importantes e que podem estar relacionados com os resultados obtidos no presente estudo.

Diante disso, foi constatado para o híbrido Hyola 571 CL que os tratamentos que apresentaram os melhores controles de azevém e nabo foram o imazapic + imazapyr e diclosulam, respectivamente. Porém estes herbicidas ocasionaram reduções significativas na produtividade de grãos da canola. A aplicação do herbicida imazaquin proporcionou um controle de $80 \%$ do nabo, mas alcançou um baixo controle de azevém (57,5\%).

O imazaquin e o nicosulfuron foram os tratamentos que melhor efetuaram o controle de nabo ao infestarem o híbrido de canola Hyola $571 \mathrm{CL}$ e, em relação ao azevém, os únicos tratamentos que apresentaram controle acima de $80 \%$ foram o imazapic+imazapyr e imazethapyr+imazapic, no entanto reduziram em torno de $50 \%$ a produtividade de grãos ao serem comparados com o imazaquin e nicosulfuron, tratamentos que demonstraram a maior produtividade de grãos.

A canola desempenha um excelente papel na rotação de culturas, por isso cada vez mais se deve aprimorar os estudos sobre essa cultura, para que além de uma maior produção essa venha a contribuir na diminuição da resistência de plantas daninhas e também para o aproveitamento de toda a estrutura que a propriedade dispõe quando cultiva o milho, a soja ou mesmo o trigo. No entanto ainda se tem muitos entraves para o cultivo da canola, e dentre esses a falta de herbicidas registrados para o controle de plantas daninhas, por esse motivo o presente estudo avaliou a possibilidade de se usar diferentes produtos, mesmo que esses não apresentem indicação para serem utilizados nessa cultura.

\section{Conclusões}

O imazapic+imazapyr e o nicosulfuron apresentam o melhor controle do azevém nos dois experimentos.

O iodosulfuron, imazethapyr+imazapic, imazapic+imazapyr, nicosulfuron, diclosulam, chlorimuronethyl e metsulfuron-methyl são eficientes no controle de nabo nos dois experimentos.

As maiores produtividades de grãos ocorrem com a aplicação de nicosulfuron e de imazaquin para a Hyola 571 CL e de imazethapyr a Hyola 575 CL.

\section{Agradecimentos}

Ao Conselho Nacional de Desenvolvimento Científico e Tecnológico (CNPq), à Fundação de Amparo à Pesquisa do Estado do Rio Grande do Sul (FAPERGS) e a Universidade Federal da Fronteira Sul (UFFS), pelo auxílio financeiro à pesquisa e pelas concessões de bolsas.

\section{Referências}

Agostinetto D, Galon L, Silva JMBV, Tironi SP, Andres A. Interferência e nível de dano econômico de capim-arroz sobre o arroz em função do arranjo de plantas da cultura. Planta Dan., 2010; 28: 993-1003. Disponível em: https:// doi.org/10.1590/So 100-83582010000500007

Agrofit/Mapa. Sistemas de Agrotóxicos Fitossanitários Consulta Aberta. Disponível e m : $<w w w$.agrofit.agricultura.gov.br/agrofit $>$. Acesso em: 20 mar. 2021.

Blackshaw RE, Lemerle D, Mailer R. Young, K. R Influence of wild radish on yield and quality of canola. Weed Sci., 2002; 50 (3): 344-349. Disponível em: https:// doi.org/10.1614/0043-1745(2002)050[0344:IOWROY] 2.0.CO;2

Brasil. Ministério da Agricultura, Pecuária e Abastecimento. Regras para Análise de Sementes. Brasília: MAPA, 2009. 395.

Cechin J, Vargas L, Agostinetto D, Zimmer V, Pertile M, Garcia JR. Resistência de biótipos de nabo ao herbicida iodosulfurom e controle alternativo. Planta Dan., 2016; 34 (1): 151-160. Disponível em: https://doi.org/10.1590/So10083582016340100016

Durigon MR, Vargas L, Chavarria G, Tomm GO. Indicações de uso e boas práticas de manejo da tecnologia Clearfield em canola para as regiões Sul e Centro-Oeste. Rev. Plantio Dir., 2016, 152 (1), 22-30. Disponível em: https://
scholar.google.com.br/Indicações de uso e boas práticas de manejo da tecnologia Clearfield em canola para as regiões Sul e Centro-Oeste

Durigon MR, Mariani F, Cechin J, Camera A.S, Vargas L, Chavarria G. Competitive ability of canola hybrids resistant and susceptible to herbicides. Planta Dan., 2019; 37:019180593. Disponível em: https://doi.org/10.1590/ So100-83582019370100133

Embrapa - Empresa brasileira de pesquisa agropecuária. Sistema brasileiro de classificação de solos. Embrapa Solos. $2013 ; 154$.

Embrapa - Empresa Brasileira de Pesquisa Agropecuária. Caracterização geral do processo produtivo agrícola. Passo Fundo, 2009. Disponível em: <http://www.cnpt.embrapa.br/ biblio/do/p_do118_8.html>. Acesso em: 20 jul. 2020.

Galon L, Forte CT, Kujawiski R, Radünz AL, David FA, Perin GF. Eficácia e fitotoxicidade de herbicidas aplicados para o manejo de plantas daninhas em cevada. Rev. Bras. de Herb., 2014; 13 (2): 105-116. Disponível em: https:// doi.org/10.7824/rbh.v13i2.274

Galon L, Agazzi LR, Vargas L, Nonemacher F, Basso FJM, Perin GF. Competitive ability of canola hybrids with weeds. Planta Dan., 2015; 33 (3): 413-423. Disponível em: https:// doi.org/10.1590/S0100-83582015000300004 
Harker KN, O'Donovan JT, Turkington TK, Blackshaw RE, Johnson EN, Brandt S. Weed interference impacts and yield recovery after four years of variable crop inputs in no-till barley and canola. Weed Techn., 2013; 27 (2): 281-290. Disponível em: https://doi.org/10.1614/WT-D-12-00115.1

Heap, I. International Herbicide-Resistant Weed Database. Herbicide Resistant Weeds in Brazil. International survey of herbicide resistant weeds. 2021. Disponível em: http:// www.weedscience.org/Summary/Country.aspx? CountryID=5. Accesso em: 19 mar. 2021.

Inmet - Instituto Nacional de Meteorologia. Disponível em <http://www.inmet.gov.br/portal/index.php?r=tempo2/ mapasPrecipitacao>. Acesso em: jul. 2020.

Lemerle D, Luckett DJ, Koetz EA, Potter T, Wu H. Seeding rate and cultivar effects on canola (Brassica napus) competition with volunteer wheat (Triticum aestivum). Crop and Pasture Sc., 2016; 67 (8): 857-863. Disponível em: https://doi.org/10.1071/CP16159

Lovarelli D, Garcia LR, Sanchez-Girón V, Bacenetti J. Barley production in Spain and Italy: Environmental comparison between different cultivation practices. Sci. of The Total Envir., 2020; 707: 135982. Disponível em: https:// doi.org/10.1016/j.scitotenv.2019.135982

Ohmes, GA, Hayes RM, Mueller T. C. Sulfentrazone dissipation in a Tennessee soil. Weed Tech., 2000; 14 (1):100 -105. Disponível em: https://doi.org/10.1614/0890-037X (2000)014[0100:SDIATS $] 2.0 . \mathrm{CO} ; 2$

Oliveira Jr RS, Koskinen WC, Ferreira FA. Sorption and leaching potential of herbicides on Brazilian soils. Weed Res., 2001; 41 (2): 97-110. Disponível em: https:// doi.org/10.1046/j.1365-3180.2001.00219.x

Oliveira AR, Freitas SP, Vieira HD. Controle de Commelina benghalensis, C. erecta, Tripogandra diuretica na cultura do café. Planta Dan., 2009; 27 (4): 823-830. Disponível em: https:// doi.org/10.1590/S0100-8358200900040002 1

Pereira LV, Carvalho BL, Dal Magro T. Controle químico de Lolium multiflorum: efeito do biótipo e da época de aplicação. Rev. de Ciências Agrov., 2017; 16 (3): 338-341. Disponível em: https://doi.org/10.5965/223811711632017338

Robinson MA, Letarte J, Cowbrough MJ, Sikkema PH, Tardif F J. Winter wheat (Triticum aestivum L.) response to herbicides as affected by application timing and temperature. Canadian Jour. of Plant Sci., 2015; 95 (2): 325-333. Disponível em: https://doi.org/10.4141/cjps-2014-109

Rodrigues BN, Almeida FS. Guia de herbicidas. $7^{\mathrm{a}}$ ed. Londrina: Edição dos autores, 2018.

Rolas - Rede oficial de laboratórios de análise de solo e de tecido vegetal. Manual de adubação e calagem para os estados do Rio Grande do Sul e Santa Catarina. Porto Alegre: Sociedade Brasileira de Ciência do Solo, 11, 2016.

Santos F, Brasil, LMM, Faria D, Silva VS, Gomes L, Vilares M. Aproveitamento integral do nabo forrageiro (Raphanus sativus L.) em processos de biorrefinaria. Eng., 2018; 20 (2): 374-393. Disponível em: https://doi.org/10.22409/ engevista.v20i2.1115

Schmitz MF, Galon L, Piovesan B, Souza MF, Agazzi LR, Forte CT, Perin GF, et al. Uso de clomazone associado ao safener dietholate para o manejo de plantas daninhas na cultura do trigo. Rev. de Ciências Agrov., 2018;17(1):2-11. $\mathrm{D}$ i s p o n íve l e m : h $\mathrm{t}$ t p s : / / doi.org/10.5965/223811711712018002

Souza GSF, Vitorino HS, Fioreze ACCL, Pereira MRR, Martins, D. Seletividade de herbicidas na cultura de crambe. Semina: Ciências Agrár., 2014; 35 (1): 161-168. Disponível em: https://doi.org/10.5433/1679-0359.2014v35n1p161

Tan S, Evans RR, Dahmer ML, Singh BK, Shaner DL. Imidazolinone-tolerant crops: history, current status and future. Pest Manag. Sci., 2005; 61 (3): 246-257. Disponível em: https://doi.org/10.1002/ps.993

Timossi PC, FreitasTT. Eficácia de nicosulfuron isolado e associado com atrazine no manejo de plantas daninhas em milho. Rev. Bras. de Herb., 2011; 10 (3): 210-218. Disponível em: https://doi.org/10.7824/rbh.v10i3.123

Tomm GO, Wiethölter S, Dalmago GA, Santos HP. Tecnologia para produção de canola no Rio Grande do Sul. Passo Fundo: Embrapa Trigo, 2009. Passo Fundo: Embrapa Trigo, 2009. html. (Embrapa Trigo. Documentos Online, 113). Disponível em: <http://www.cnpt.embrapa.br/biblio/ do/p_do113.htm >. Acessado em: 17 nov. 2020.

Torres LG, Ferreira EA, Rocha PRR, Faria AT, Gonçalves VA, Galon L. Alterações nas características fisiológicas de cultivares de cana-de-açúcar submetida à aplicação de herbicidas. Planta Dan., 2012; 30 (3): 581-587. Disponível e m : ht t p s : / / w w w s c i e lo.b r / j/ pd / a/577FwcvXmL6BP459WpL7NCR/?format=pdf\&lang=pt.

Vargas L, Fraga DS, Agostinetto D, Mariani F, Duarte TV, Silva BM. Dose-response curves of Lolium multiflorum biotypes resistant and susceptible to clethodim. Planta Dan., 2013: 31 (4): 887-892. Disponível em: https:// doi.org/10.1590/S0100-83582013000400015

Vargas L, Henckes JR, Schmitz MF, Piasecki C, Cechin J, Torchelsen, J. Caracterização e manejo de azevém (Lolium multiflorum L.) resistente a herbicidas em áreas agrícolas. Rev. Plantio Dir., 2018; 162 (1): 15-19. Disponível em: https://www.alice.cnptia.embrapa.br/bitstream/ doc/1091629/1/ID443262018v28n162p15PlantioDireto.pdf. 
Velini ED, Osipe R, Gazziero DLP. Procedimentos para instalação, avaliação e análise de experimentos com herbicidas. Londrina: SBCPD, 1995.

Xu J, ZhangJ, Dong F, Liu X, Zhu G, Zheng, Y. A multiresidue analytical method for the detection of seven triazolopyrimidine sulfonamide herbicides in cereals, soybean and soil using the modified QuEChERS method and UHPLC -MS/MS. Anal. Meth., 2015; 7 (23): 9791-9799. Disponível em: https://doi.org/10.1039/C5AY01622C

Zare M, Bazrafshan F, Mostafavi K. Competition of rapeseed (Brassica napus L.) cultivars with weeds. African Jour. of Biot., 2012; 11 (6): 1378-1385. Disponível em: https:// doi.org/10.5897/AJB1 1.1909

Zuo Q, Kuai J, Zhao L, Hu Z, Wu J, Zhou, G. The effect of sowing depth and soil compaction on the growth and yield of rapeseed in rice straw returning field. Field Crops Res., 2017; 203 (1): 47-54. Disponível em: https://doi.org/10.1016/ j.fcr.2016.12.016 